\title{
Effect of the COVID-19 pandemic on malaria intervention coverage in Nigeria: Analysis of the Premise Malaria COVID-19 Health Services Disruption Survey 2020
}

\author{
Olayinka S. Ilesanmi ${ }^{1}$, Aanuoluwapo A. Afolabi ${ }^{1}$, Opeyemi P. Iyiola ${ }^{2}$
}

\author{
AFFILIATION \\ 1 Department of Community Medicine, College of Medicine, University \\ of Ibadan, Ibadan, Nigeria \\ 2 Department of Community Medicine, University College Hospital, \\ Ibadan, Nigeria
}

\section{CORRESPONDENCE TO}

Aanuoluwapo A. Afolabi. Department of Community Medicine, College of Medicine, University of Ibadan, 200132, Ibadan, Oyo State,
Nigeria. E-mail: afoannade@gmail.com

ORCID ID: https://orcid.org/0000-0001-9928-2252

KEYWORDS

COVID-19, COVID-19 control, malaria, malaria control, rollback malaria, Nigeria

Received: 7 June 2021, Revised: 13 August 2021, Accepted: 6 September 2021

https://doi.org/10.18332/popmed/141979
$485(50.5 \%)$ people aged $\leq 25$ years visited healthcare facilities $\left(\chi^{2}=15.923, p \leq 0.001\right)$, while 385 (39.9\%) persons aged $\leq 25$ years visited healthcare facilities during the pandemic $\left(\chi^{2}=15.53, \mathrm{p} \leq 0.001\right)$. Among those with graduate/ postgraduate education who visited healthcare facilities, $593(45.9 \%)$ paid visits before the pandemic $\left(\chi^{2}=7.33\right.$, $\mathrm{p}=0.026)$, while $445(44.4 \%)$ paid visits during the pandemic $\left(\chi^{2}=16.37, p \leq 0.001\right)$. Individuals aged $26-35$ years had 21\% less odds (AOR=0.79; 95\% CI: $0.65-0.97, p=0.021)$ of visiting healthcare facilities before the pandemic, and $23 \%$ less odds of visiting healthcare facilities during the pandemic (AOR=0.77; 95\% CI: 0.63-0.95, p=0.013).

CONCLUSIONS The COVID-19 pandemic has had a negative impact on visits to healthcare facilities for malarial treatment. To promote malaria intervention during the pandemic, malaria diagnosis should be linked with COVID-19 screening and testing.

\section{INTRODUCTION}

The first case of the novel Coronavirus disease (COVID-19) was reported in Wuhan, China, during the fall of $2019^{1}$. By 11 March 2020, COVID-19 was declared a pandemic by the World Health Organization (WHO) after more than 100000 individuals had been infected with SARS-CoV-2 ${ }^{2}$. Nigeria reported the first case of COVID-19 on 27 February 2020 and had recorded less than 1000 COVID-19 cases by 31 March $2020^{2,3}$. Due to the highly infectious nature of COVID-19, many countries instituted lockdown measures to curtail its spread ${ }^{3,4}$. In Nigeria, some hospitals initially suspended operations to reduce staff exposure to the public 5 . Paradoxically, patients also minimized their hospital visits to avoid contact with the hospital staff, whom they considered high-risk and other infected patients. As a result, managing various ailments and diseases like hypertension, diabetes mellitus, and malaria were challenging to carry out.

Nearly one-half of the world population lives in malariaendemic countries ${ }^{6}$. Malaria is one of the life-threatening diseases endemic to Africa. Out of every ten malaria deaths, 9 occur in Sub-Saharan Africa, reportedly more among pregnant women and children aged $<5$ years ${ }^{7}$. The economic loss due to malaria in Africa is estimated at more than 2 billion US dollars annually. It is known that poverty exacerbates the malaria situation, and malaria contributes to the poverty of the region. Thus, it is believed that malaria 
is directly responsible for a growing deficit of up to $1.3 \%$ per year in some African countries ${ }^{7}$. The yearly economic loss due to malaria in Nigeria has been placed at 132 billion NGN (1000 Nigerian Naira about US\$2.4) in terms of treatment costs, prevention, and loss of man-hours ${ }^{8}$.

Various malaria intervention programs were introduced by the government and its partners in order to reduce its scourge and eliminate malaria in Africa ${ }^{9}$. Key among them is the rollback malaria (RBM) initiative that was signed in Dakar, Senegal, in 1998 by various multilateral organizations, including the United Nations Children's Fund, WHO, and the African Union ${ }^{8}$. It recommends the use of long-lasting insecticide-treated nets (ITNs), intermittent preventive therapy and case management, as part of the measures to reduce the burden of malaria in vulnerable communities, particularly among pregnant women and children below five years of age $\mathrm{e}^{9}$. The RBM program was launched in Nigeria in 2000 and resulted in a 30\% decline in malaria incidence between 2001 and $2013^{8}$. Data from the Nigeria Demographic Health Survey 2018, reported that malaria prevalence among children $<5$ years has decreased from $42 \%$ in 2013 to $23 \%$ in 2018. Malaria testing is cost-intensive in Nigeria, both in public and private healthcare facilities ${ }^{10}$. Malaria treatment-seeking behavior is generally poor in Nigeria, with a large proportion practicing self-medication.

In their research on the indirect effects of the COVID-19 pandemic on malaria intervention coverage in Africa, Weiss et al. ${ }^{11}$ stated that the disruption to malarial intervention during the COVID-19 lockdown could almost double malaria mortality in 2020 and potentially lead to higher mortality rates in subsequent years. Malaria-related deaths frequently occur in Nigeria (Figure 1$)^{12}$. Seasonality has been implicated in the understanding of malaria cases and deaths, with a higher proportion of malaria cases and deaths reported during the rainy season. Antimalarials have helped to keep malaria cases and deaths at a minimum. If access to antimalarials and malaria treatment gets disrupted, the impact on deaths is significant - up to 100000 additional malaria deaths could occur. Under a scenario of disruptions to essential malaria services, such as reduction in case management, the impact could be profound. Therefore, it is important to assess the impact of the malaria intervention coverage before and during the COVID-19 pandemic ${ }^{13}$. The findings from this study would help design programs that will help sustain progress made on malaria intervention coverage in the future. This study, therefore, aimed to access the uptake of malaria intervention services in Nigeria before and during the COVID-19 pandemic.

\section{METHODS}

\section{Study area}

This study utilized the data collected for Nigeria in the COVID-19 Health Services Disruption Survey 202014. The other countries where data were also collected were Benin, Burkina Faso, Côte d'Ivoire, Democratic Republic of the Congo, Ethiopia, Ghana, Kenya, Liberia, Mali, Mozambique, Niger, Rwanda, Senegal, Sierra Leone, Somalia, Tanzania, Uganda, Zambia, and Zimbabwe. Nigeria is the largest country with the most buoyant economy in west Africa, with an estimated population of 206 million $^{15}$.

\section{Data collection}

Data used were extracted from the COVID-19 Health Services Disruption Survey 2020. The period covered in the survey was December 2019 - July 2020. The pre-COVID-19 period was defined as December 2019 - February 2020, while the COVID-19 period was defined as March-July 2020. Information on health services disruption was collected using a questionnaire-based survey which covered both periods. The data were collected throughout July 2020

Figure 1. Age-related trend in malaria deaths in Nigeria between 1990 and $2017^{12}$

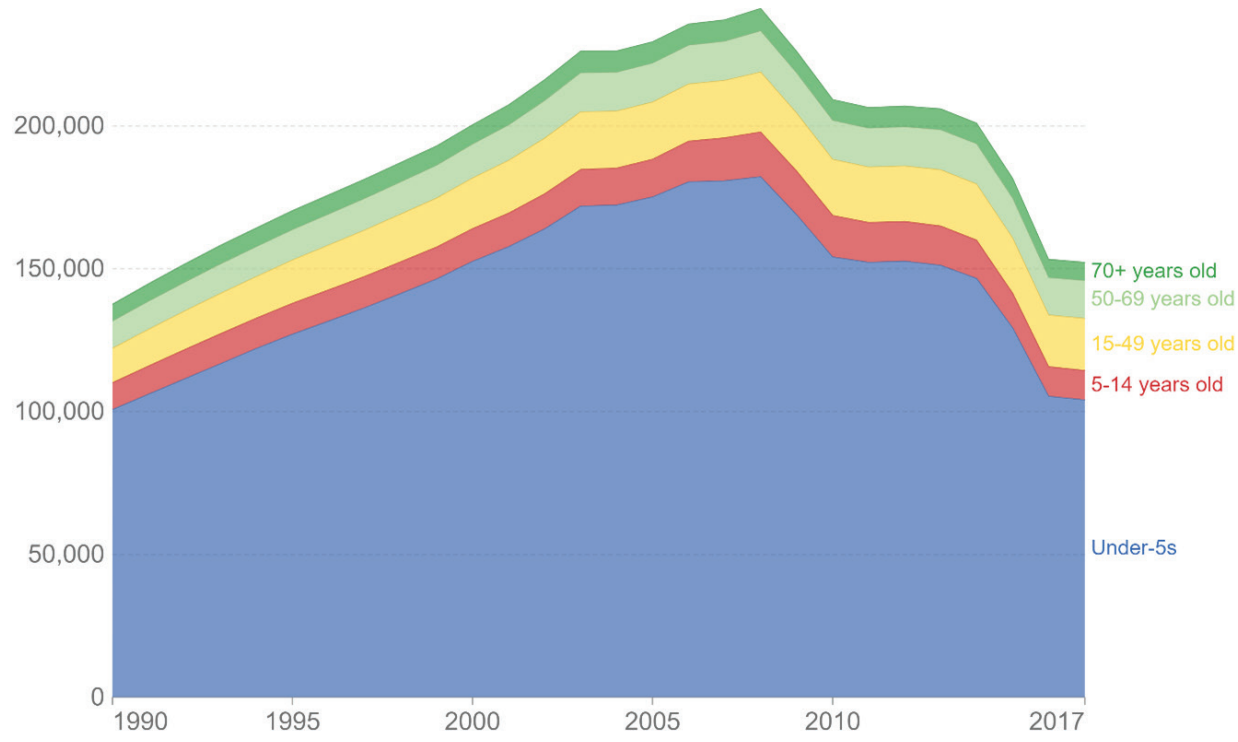


from members of the public who had access to both smart phones and internet connections using the Premise platform. Premise is a smartphone-based application that provides data collection capabilities throughout the world. The survey was designed by the Institute for Health Metrics and Evaluation (IHME) in collaboration with the Bill and Melinda Gates Foundation and was implemented by Premise. Incoming data were reviewed and validated by Premise and then transferred to IHME, where they underwent further verification and stored in secure databases maintained by IHME $^{14}$.

The questionnaire had two sections. Section A described sociodemographic characteristics such as age, sex, location, occupation, ethnicity, religion, financial situation, and an average number of persons in the household. In section B, survey questions pertaining to malaria were divided into two periods: before and during the COVID-19 pandemic. Questions for the period before the COVID-19 pandemic included: 'Were you able to visit healthcare facilities during December - February?'; 'What was the reason you were not able to visit healthcare facilities during December - February?'; 'How many times did you visit healthcare facilities during December - February?'; 'Did you have malaria symptoms during December - February?'; 'Were you tested for malaria during December - February?'; and 'What antimalaria medication did you use during December - February?'.

Questions for the COVID-19 pandemic period included: 'Were you able to visit healthcare facilities since March?'; 'What was the reason you were not able to visit a healthcare facility since March?'; 'How many times did you visit a healthcare facility since March?'; 'Have you had malaria symptoms since March?'; 'Have you been tested for malaria since March?'; and 'What antimalaria medication did you use since March?'.

\section{Sampling/population}

IHME, Bill and Melinda Gates Foundation, and Premise, determined target quotas for each country prior to data collection. Target quotas were based primarily on the size of the Premise user network in each country. Progress towards target quotas was monitored over the course of data collection. In locations where the number of responses fell significantly below target quotas, then Premise actively promoted the survey through measures such as re-engagement campaigns and targeted advertisements to increase the number of respondents. Weights were not calculated for the malaria disruption survey. Individual data were available for 1986 Nigerians. However, the completeness of the data was $99.9 \%$.

\section{Statistical analysis}

The IBM SPSS Statistics for Windows Version 25.0. IBM Corp. $2017^{16}$ was used. Descriptive statistics were conducted on sociodemographic variables. Bivariate analysis, using chi-

squared tests, were used to determine the association between malaria preventive practices before and during the COVID-19 pandemic in Nigeria. These included the number of ITNs, presence of malaria symptoms, visits to a healthcare provider, number of visits, and enrolment in malaria tests. The variable 'Paid visit to healthcare facilities' was used as an indicator of willingness to seek malaria treatment. The association between paid visit to healthcare facilities and sociodemographic characteristics of respondents was determined using chi-squared tests. Binary logistic regression tests were independently conducted on significant variables at the bivariate level both for before and during the COVID-19 pandemic. The significant variables at the two periods were modelled into two regression analyses: before and during the COVID-19 pandemic. Thus, all the significant variables were controlled for in the logistic regression models. The level of statistical significance was set at $\mathrm{p}<0.05$.

\section{RESULTS}

Among the 1985 respondents, 1522 (76.7\%) were males, and $960(48.4 \%)$ were aged $\leq 25$ years. Also, 711 (35.8\%) lived in the city or metropolitan area, and 1292 (65.1\%) had attained graduate/postgraduate educational level. In addition, 733 (36.9\%) belonged to the Yoruba ethnic group, 1033 (52.0\%) were Christians, and 1115 (56.2\%) lived with four or more persons in their households (Table 1).

Table 2 shows the characteristics of malaria preventive practices among respondents before (December 2019 - February 2020) and during the COVID-19 pandemic (March-July 2020). Before the COVID-19 pandemic, 338 $(28.5 \%)$ had three or more ITNs, and during the COVID-19 pandemic $286(34.7 \%)$ had three or more ITNs $\left(\chi^{2}=8.36\right.$,

Table 1. Sociodemographic characteristics of respondents in Malaria Premise survey, 2020

\begin{tabular}{l|r|r|}
\hline Characteristics & n & $\%$ \\
\hline Sex (n=1985) & 1522 & 76.7 \\
Male & 449 & 22.6 \\
Female & 14 & 0.7 \\
Prefer not to answer & & \\
Age (years) (n=1985) & 960 & 48.4 \\
$\leq 25$ & 839 & 42.3 \\
$26-35$ & 186 & 9.4 \\
$>35$ & & \\
\hline Location (n=1975) & 711 & 35.8 \\
City center or metropolitan area & 736 & 37.1 \\
Suburban/peri-urban & 538 & 27.1 \\
Rural & & \\
Education level (n=1985) & 51 & 2.6 \\
Primary or lower & 642 & 32.3 \\
Secondary/technical/high school & 1292 & 65.1 \\
Graduate/postgraduate & & Continued
\end{tabular}


Table 1. Continued

\begin{tabular}{|c|c|c|}
\hline Characteristics & $\mathbf{n}$ & $\%$ \\
\hline \multicolumn{3}{|l|}{ Occupation (n=1985) } \\
\hline Employed & 828 & 41.7 \\
\hline Student & 1003 & 50.5 \\
\hline Unemployed & 154 & 7.8 \\
\hline \multicolumn{3}{|l|}{ Ethnicity (n=1985) } \\
\hline Yoruba & 733 & 36.9 \\
\hline Hausa & 471 & 23.7 \\
\hline Igbo & 301 & 15.2 \\
\hline Other & 480 & 24.2 \\
\hline \multicolumn{3}{|l|}{ Religion (n=1985) } \\
\hline Christianity & 1033 & 52.0 \\
\hline Islam & 937 & 47.2 \\
\hline Other & 15 & 0.8 \\
\hline \multicolumn{3}{|l|}{ Financial situation (n=1985) } \\
\hline $\begin{array}{l}\text { Can comfortably afford food, but have no } \\
\text { savings }\end{array}$ & 1,308 & 65.9 \\
\hline Cannot afford enough food for the family & 492 & 24.8 \\
\hline Can comfortably afford food, and have savings & 185 & 9.3 \\
\hline \multicolumn{3}{|l|}{$\begin{array}{l}\text { Number of people in the household } \\
(n=1985)\end{array}$} \\
\hline$\leq 4$ & 1,115 & 56.2 \\
\hline$>4$ & 870 & 43.8 \\
\hline
\end{tabular}

$\mathrm{p}=0.004)$. Before the COVID-19 pandemic, 1104 (55.6\%) had malarial symptoms, and during the COVID-19 pandemic $881(44.4 \%)$ had malarial symptoms $\left(\chi^{2}=42.759, p \leq 0.001\right)$. Before the COVID-19 pandemic, 927 (84.0\%) had paid a visit to healthcare providers, and during the COVID-19 pandemic, $708(79.3 \%)$ had paid a visit to healthcare providers $\left(\chi^{2}=6.99, p=0.008\right)$. Furthermore, $482(70.8 \%)$ tested positive for malaria before the COVID-19 pandemic, while $313(62.6 \%)$ tested positive for malaria during the COVID-19 pandemic $\left(\chi^{2}=8.40, p=0.004\right)$.

Figure 2 describes the self-reported reasons for respondents' failure to visit a healthcare provider for malaria diagnosis and testing before and during the COVID-19 pandemic. Due to the closure of health facilities, 152 (28.2\%) did not visit health providers before the COVID-19 pandemic, while 141 (32.3\%) did not visit health providers during the COVID-19 pandemic. During the COVID-19 pandemic, $20(4.6 \%)$ did not visit health providers because they were unable to access health facilities due to lockdown restrictions. On the other hand, 18 (4.1\%) attributed their failure to visit health providers due to the unavailability of test for malaria during the COVID-19 pandemic.

The frequently used medications for the treatment of malaria before the COVID-19 pandemic included Amodiaquine, Artemisinin Combination therapy, Chloroquine, Fansidar, Artesunate injection, and Primaquine,

Table 2. Characteristics of malarial preventive practices among respondents before and during the COVID-19 pandemic among the Nigerian population, 2020

\begin{tabular}{|c|c|c|c|c|}
\hline Variables & $\begin{array}{c}\text { Before } \\
\text { n (\%) }\end{array}$ & $\begin{array}{c}\text { During } \\
\text { n (\%) }\end{array}$ & $\chi^{2}$ & $\mathbf{p}$ \\
\hline \multicolumn{5}{|c|}{ Number of insecticide-treated nets } \\
\hline$\leq 2$ & $848(71.5)$ & $539(65.3)$ & 8.362 & 0.004 \\
\hline$\geq 3$ & $338(28.5)$ & $286(34.7)$ & & \\
\hline \multicolumn{5}{|c|}{ Presence of malaria symptoms } \\
\hline Yes & $1104(55.6)$ & $897(45.2)$ & 42.759 & $<0.001$ \\
\hline No & $881(44.4)$ & $1088(54.8)$ & & \\
\hline \multicolumn{5}{|c|}{ Paid visit to healthcare facilities } \\
\hline Yes & $927(84.0)$ & $708(79.3)$ & 6.986 & 0.008 \\
\hline No & $177(16.0)$ & $185(20.7)$ & & \\
\hline \multicolumn{5}{|c|}{ Number of visits to healthcare facilities } \\
\hline 1 & $343(37.0)$ & $278(39.3)$ & 0.845 & 0.358 \\
\hline$>1$ & $584(63.0)$ & $430(60.7)$ & & \\
\hline \multicolumn{5}{|c|}{ Enrolled in malaria test } \\
\hline Yes & $681(73.5)$ & $501(71.7)$ & 0.556 & 0.456 \\
\hline No & $246(26.5)$ & $198(28.3)$ & & \\
\hline \multicolumn{5}{|c|}{ Tested positive for malaria } \\
\hline Yes & $482(70.8)$ & $313(62.6)$ & 8.397 & 0.004 \\
\hline No & 199 (29.2) & $187(37.4)$ & & \\
\hline \multicolumn{5}{|c|}{ Treated for malaria with medicine } \\
\hline Yes & $476(98.8)$ & $302(96.8)$ & 2.760 & 0.096 \\
\hline No & $6(1.2)$ & $10(3.2)$ & & \\
\hline
\end{tabular}


Figure 2. Self-reported reasons for failure to visit a healthcare provider for malaria diagnosis and testing before and during the COVID-19 pandemic, 2020

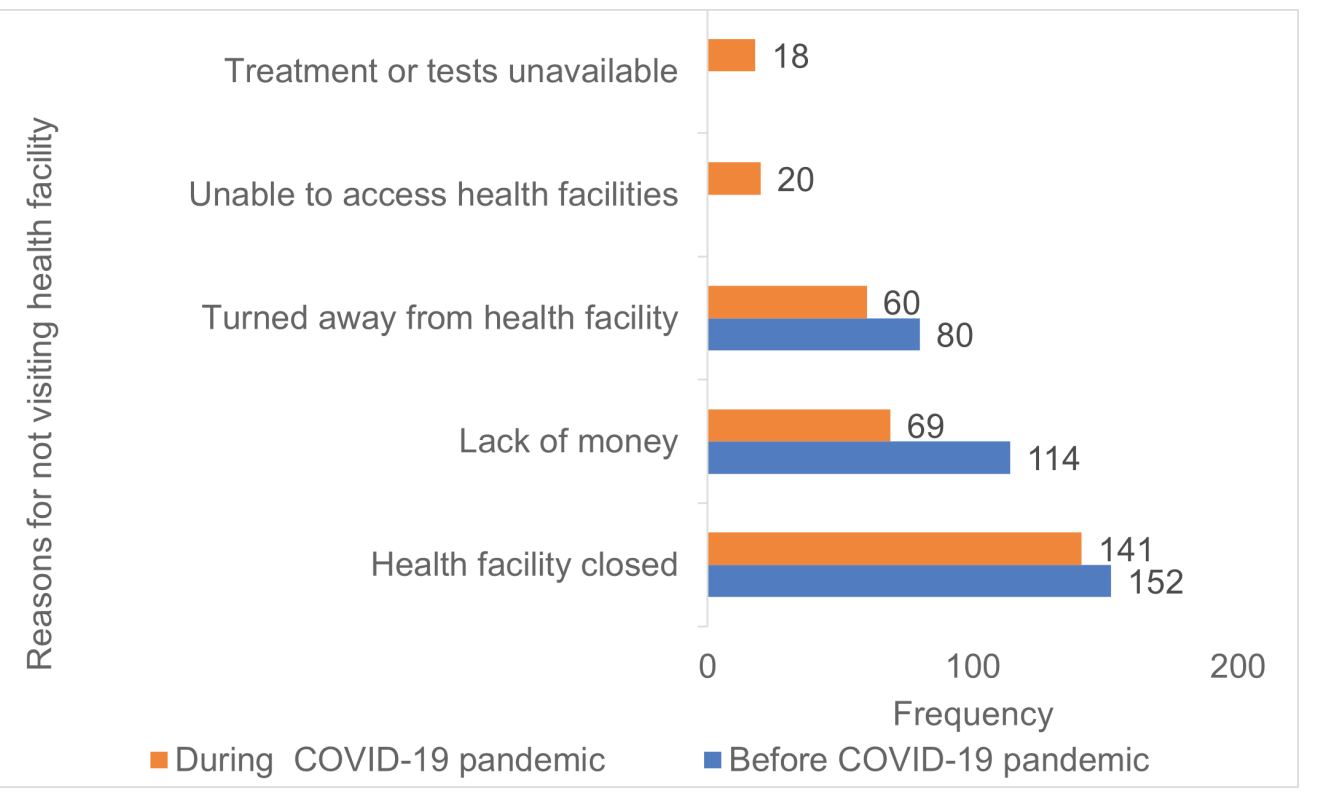

during the COVID-19 pandemic they also included Artesunate rectal pills. Among the $6(1.2 \%)$ persons who did not use medications for malarial treatment before the COVID-19 pandemic, $3(50.0 \%)$ stated their unwillingness to use medications, $2(33.3 \%)$ did not use medications due to the side effects, and $1(16.7 \%)$ did not use medications due to the lack of money. Among the 10 (3.2\%) who did not use antimalarial medications during the COVID-19 pandemic, 3 $(30.0 \%)$ stated their unwillingness to use medications, and 3 (30.0\%) did not use medications due to financial constraints. In addition, $2(20.0 \%)$ did not use medications due to the fear of side effects, and $2(20.0 \%)$ did not use medications due to the unavailability of medicines at the health facility.

Before the COVID-19 pandemic, 485 (50.5\%) people aged $\leq 25$ years visited healthcare facilities compared to 348
(41.5\%) aged 26-35 years, and 94 (50.5\%) persons aged $\geq 35$ years $\left(\chi^{2}=15.93, p \leq 0.001\right)$. Also, $593(45.9 \%)$ individuals with graduate/postgraduate education paid visits to healthcare facilities compared to $18(72.0 \%)$ with primary or lower education, and 310 (48.3\%) with secondary/technical/ high school education $\left(\chi^{2}=7.33, p=0.026\right)$ (Table 3).

During the COVID-19 pandemic, 385 (39.9\%) persons aged $\leq 25$ years visited healthcare facilities compared to $260(31.0 \%)$ aged $26-35$ years, and $64(34.9 \%)$ aged $>35$ years $\left(\chi^{2}=15.53, \mathrm{p} \leq 0.001\right)$. Also, $445(44.4 \%)$ with graduate/postgraduate education visited healthcare facilities compared to $18(72.0 \%)$ with primary education, and 243 (37.9\%) with secondary/technical/high school $\left(\chi^{2}=16.37\right.$, $\mathrm{p} \leq 0.001$ ) (Table 3).

Before the COVID-19 pandemic, individuals aged 26-

Table 3. Association between sociodemographic characteristics and visit to healthcare provider before and during COVID-19 pandemic, 2020

\begin{tabular}{|c|c|c|c|c|}
\hline \multirow[t]{2}{*}{ Variables } & \multicolumn{2}{|c|}{ Before } & \multicolumn{2}{|c|}{ During } \\
\hline & $\begin{array}{c}\text { Yes } \\
\text { n (\%) }\end{array}$ & $\begin{array}{c}\text { No } \\
\text { n (\%) }\end{array}$ & $\begin{array}{c}\text { Yes } \\
\text { n (\%) }\end{array}$ & $\begin{array}{c}\text { No } \\
\text { n (\%) }\end{array}$ \\
\hline \multicolumn{5}{|l|}{ Sex } \\
\hline Male & $729(47.9)$ & $793(52.1)$ & $565(37.1)$ & 957 (62.9) \\
\hline \multirow[t]{2}{*}{ Female } & $193(43.0)$ & $256(57.0)$ & $137(30.5)$ & $312(69.5)$ \\
\hline & \multicolumn{2}{|c|}{$\chi^{2}=3.362, p=0.067$} & \multicolumn{2}{|c|}{$\chi^{2}=6.606, p=\mathbf{0 . 0 1 0}$} \\
\hline \multicolumn{5}{|l|}{ Age (years) } \\
\hline$\leq 25$ & $485(50.5)$ & $475(49.5)$ & 383 (39.9) & $577(60.1)$ \\
\hline $26-35$ & $348(41.5)$ & $491(58.5)$ & $260(31.0)$ & $575(69.0)$ \\
\hline \multirow[t]{2}{*}{$>35$} & $94(50.5)$ & $92(49.5)$ & $65(34.9)$ & $121(65.1)$ \\
\hline & \multicolumn{2}{|c|}{$\chi^{2}=15.923, \mathrm{p} \leq \mathbf{0 . 0 0 1}$} & \multicolumn{2}{|c|}{$\chi^{2}=15.525, p \leq \mathbf{0 . 0 0 1}$} \\
\hline
\end{tabular}


Table 3. Continued

\begin{tabular}{|c|c|c|c|c|}
\hline \multirow[t]{2}{*}{ Variables } & \multicolumn{2}{|c|}{ Before } & \multicolumn{2}{|c|}{ During } \\
\hline & $\begin{array}{c}\text { Yes } \\
\text { n (\%) }\end{array}$ & $\begin{array}{c}\text { No } \\
\text { n (\%) }\end{array}$ & $\begin{array}{c}\text { Yes } \\
\text { n (\%) }\end{array}$ & $\begin{array}{c}\text { No } \\
\text { n (\%) }\end{array}$ \\
\hline \multicolumn{5}{|l|}{ Location } \\
\hline City center or metropolitan area & $363(51.1)$ & $348(48.9)$ & $273(38.4)$ & $438(61.6)$ \\
\hline Suburban/peri-urban & $266(36.1)$ & $470(63.1)$ & $196(26.6)$ & $540(73.4)$ \\
\hline \multirow[t]{2}{*}{ Rural } & $298(55.4)$ & $240(44.6)$ & $239(44.4)$ & $299(55.6)$ \\
\hline & \multicolumn{2}{|c|}{$\chi^{2}=54.706, p \leq \mathbf{0 . 0 0 1}$} & \multicolumn{2}{|c|}{$\chi^{2}=46.481, \mathrm{p} \leq \mathbf{0 . 0 0 1}$} \\
\hline \multicolumn{5}{|l|}{ Education level } \\
\hline Primary or lower & $18(72.0)$ & $7(28.0)$ & $18(72.0)$ & $7(28.0)$ \\
\hline Secondary/technical/high school & $310(48.3)$ & $332(51.7)$ & $243(37.9)$ & $399(62.1)$ \\
\hline \multirow[t]{2}{*}{ Graduate/postgraduate } & $593(45.9)$ & $699(54.1)$ & $445(34.4)$ & $847(65.6)$ \\
\hline & \multicolumn{2}{|c|}{$\chi^{2}=7.329, p=\mathbf{0 . 0 2 6}$} & \multicolumn{2}{|c|}{$\chi^{2}=16.368, \mathrm{p} \leq \mathbf{0 . 0 0 1}$} \\
\hline \multicolumn{5}{|l|}{ Occupation } \\
\hline Employed & $504(46.6)$ & $537(53.4)$ & $398(36.8)$ & $683(63.2)$ \\
\hline \multirow[t]{2}{*}{ Unemployed } & $423(46.8)$ & $481(53.2)$ & $310(34.3)$ & $594(65.7)$ \\
\hline & \multicolumn{2}{|c|}{$\chi^{2}=0.006, p=0.940$} & \multicolumn{2}{|c|}{$\chi^{2}=1.369, p=0.242$} \\
\hline
\end{tabular}

35 years had $21 \%$ less odds of paying visits to healthcare facilities compared to those aged $\leq 25$ years (AOR=0.79; $95 \%$ CI: $0.65-0.97, p=0.021)$. However, those aged $>35$ years had more odds of paying visits to healthcare facilities compared to those aged $\leq 25$ years $(\mathrm{AOR}=1.06$; 95\% CI: $0.77-1.46$, $\mathrm{p}=0.732$ ). Also, those with primary or lower education level had nearly three times the odds of visiting healthcare facilities compared to those with graduate/postgraduate education (AOR=2.54; 95\% CI: 1.04-6.20, p=0.041) (Table 4).

During the COVID-19 pandemic, individuals aged 26-35 years had $23 \%$ fewer odds of paying visits to healthcare facilities compared to those aged $\leq 25$ years $(\mathrm{AOR}=0.77$;
95\% CI: $0.63-0.95, \mathrm{p}=0.013)$. Individuals aged $>35$ years had nearly $15 \%$ fewer odds of paying visits to healthcare facilities compared to those aged $\leq 25$ years $(A O R=0.85$; $95 \% \mathrm{CI}: 0.60-1.19, \mathrm{p}=0.343)$. Also, individuals with primary or lower education level had nearly four times the odds of paying visits to healthcare facilities compared to those with graduate/postgraduate education (AOR=3.84; 95\% CI: $1.56-$ 9.45, $\mathrm{p}=0.003$ ) (Table 4).

\section{DISCUSSION}

This study found that more households used ITNs during the COVID-19 pandemic compared to the period before the

Table 4. Determinants of visits to healthcare facilities for management of malaria before and during the COVID-19 pandemic among the Nigerian population, 2020

\begin{tabular}{|c|c|c|c|c|}
\hline \multirow[t]{2}{*}{ Variables* } & \multirow[t]{2}{*}{ AOR } & \multicolumn{2}{|c|}{$95 \%$ CI } & \multirow[t]{2}{*}{ p } \\
\hline & & Lower & Upper & \\
\hline \multicolumn{5}{|c|}{ Paid visit to healthcare facilities before COVID-19 pandemic } \\
\hline \multicolumn{5}{|l|}{ Age (years) } \\
\hline$\leq 25$ & 1 & & & \\
\hline $26-35$ & 0.793 & 0.650 & 0.966 & 0.021 \\
\hline$>35$ & 1.058 & 0.765 & 1.463 & 0.732 \\
\hline \multicolumn{5}{|l|}{ Location } \\
\hline City center or metropolitan area & 0.570 & 0.460 & 0.705 & $<0.001$ \\
\hline Suburban/peri-urban & 1.146 & 0.911 & 1.441 & 0.243 \\
\hline Rural & 1 & & & \\
\hline \multicolumn{5}{|l|}{ Education level } \\
\hline Primary or lower & 2.539 & 1.040 & 6.197 & 0.041 \\
\hline Secondary/technical/high school & 1.022 & 0.837 & 1.248 & 0.831 \\
\hline Graduate/postgraduate & 1 & & & \\
\hline
\end{tabular}


Table 4. Continued

\begin{tabular}{|c|c|c|c|c|}
\hline \multirow[t]{2}{*}{ Variables* } & \multirow[t]{2}{*}{ AOR } & \multicolumn{2}{|c|}{$95 \%$ CI } & \multirow[t]{2}{*}{ p } \\
\hline & & Lower & Upper & \\
\hline \multicolumn{5}{|c|}{ Paid visit to healthcare facilities during COVID-19 pandemic } \\
\hline \multicolumn{5}{|l|}{ Sex } \\
\hline Male & 1.219 & 0.967 & 1.538 & 0.094 \\
\hline Female & 1 & & & \\
\hline \multicolumn{5}{|l|}{ Age (years) } \\
\hline$\leq 25$ & 1 & & & \\
\hline $26-35$ & 0.770 & 0.625 & 0.947 & 0.013 \\
\hline$>35$ & 0.848 & 0.603 & 1.192 & 0.343 \\
\hline \multicolumn{5}{|l|}{ Location } \\
\hline City center or metropolitan area & 0.510 & 0.400 & 0.651 & $<0.001$ \\
\hline Suburban/peri-urban & 0.844 & 0.668 & 1.066 & 0.155 \\
\hline Rural & 1 & & & \\
\hline \multicolumn{5}{|l|}{ Education level } \\
\hline Primary or lower & 3.841 & 1.560 & 9.454 & 0.003 \\
\hline Secondary/technical/high school & 1.041 & 0.845 & 1.282 & 0.709 \\
\hline Graduate/postgraduate & 1 & & & \\
\hline
\end{tabular}

*Factors that were included in the adjusted odds ratio. All the variables were adjusted for because significant variables during each period were modelled into the regression analysis. AOR: adjusted odds ratio.

pandemic. The endemicity of malaria in Nigeria and public health campaigns on the use of ITNs as malarial preventive measures ${ }^{17}$ could provide some explanation for this. In a bid to reduce the risk of contracting COVID-19 in hospital settings, many individuals could have been encouraged to adopt the use of ITNs as a malaria preventive strategy. The COVID-19 pandemic made a lot of people aware of their health and placed a premium on it. COVID-19 information generally exposed them to more health education via the various traditional and social media, because they spent more time at home. Findings from this study revealed that fewer people had symptoms of malaria during the COVID pandemic than the period before the COVID-19 pandemic. There is a possibility that some malarial symptoms were ascribed to COVID-19 due to the similarities between the two infections. Cameroon et al. ${ }^{18}$ reported a significant intricate relationship between COVID-19 and malaria cases.

It is known that the major drivers of infectious diseases, including COVID-19, are economic collapse and health system failure. Findings from studies conducted in Venezuela, Brazil, and Colombia, reveal that nearly $90 \%$ of total malaria cases are attributed to recent migration ${ }^{19}$. The COVID-19 pandemic caused a substantial economic impact globally, thus causing malaria resurgence in these regions, although its extent has not been adequately documented.

Also, there was a noticeable decline in visits to health providers before COVID-19 compared to during the pandemic. The major reason given was the closure of health facilities. An underlying explanation for the closure of health facilities in Nigeria is the many episodes of industrial action embarked on by healthcare workers. Poor healthcare leadership and management have been identified as some of the most common causes of industrial action among healthcare workers, regardless of the cadre ${ }^{20}$. Closure of health facilities during the COVID-19 pandemic was adopted as one of the proven public health safety measures required to break the chain of COVID-19 transmission $^{21}$. It was, therefore, likely that sick people either patronized patent and proprietary medicine vendors or practiced selfmedication ${ }^{22-24}$. Rogerson et al. ${ }^{25}$ also stated similar reasons that individuals stopped attending health facilities due to fear of exposure to COVID-19 or financial constraints, and healthcare workers required additional resources to protect themselves from COVID-1925. Black et al. ${ }^{25,26}$ noted that healthcare staff shortages due to COVID-19 illness could have discouraged people from hospital consultations.

Findings from this study revealed that young people (aged $<25$ years) had higher odds of visiting health facilities for the management of malaria both before and during the COVID-19 pandemic. This finding elucidates that younger people are more health literate regarding the standard index of prompt malaria detection and commencement of management. Evidence from literature reports that malaria symptoms such as fever recede with increasing age ${ }^{27,28}$. Thus, younger people are more likely to develop these symptoms and seek prompt case management options. To improve visits to healthcare facilities when malaria infection is suspected among older people, invigoration of public health campaigns on the need for diagnostic treatment is required. An interesting factor to explore is that health decisions, such as paying visit to 
health facilities for case management of malaria, are often taken by older persons, who are responsible for the welfare of younger persons.

In the period before and during the COVID-19 pandemic, those with lower education level had a higher likelihood of visiting healthcare facilities to seek malaria management compared with those with higher education levels. Thus, it could be inferred that educated persons are more likely to practice self-medication once they develop malaria symptoms. In addition, individuals with low level of education have good health literacy regarding the adequate management of malaria in healthcare facilities. Therefore, strategies for improving malaria-related health literacy among highly educated persons should be considered. For instance, awareness campaigns should be tailored towards educated persons. Active engagement of the modern media platforms, such as WhatsApp, Instagram, and Twitter should be undertaken.

During the COVID-19 pandemic, males were found to have a higher likelihood for healthcare visits for management of malaria. This elucidates that women are less likely to visit the hospital for malaria care. Evidence from the Nigeria Demographic Health Survey reports that $52 \%$ of women sleep under ITNs. This could therefore indicate that females adopt malaria preventive practices, such as sleeping under ITNs, more compared to males ${ }^{29}$. Thus, more males are likely to be infected with malaria and visit healthcare facilities to seek care. The use of ITNs among all members of the population, especially men, should be promoted.

From this study, we identified that individuals who lived in suburban or rural areas were more likely to visit healthcare facilities for malaria management compared to those in urban areas. This finding could be due to the presence of socioeconomic and housing factors such as good income (above the national minimum wage), furnished wall, and the absence of orifices that are protective against malaria in urban areas. As a result, residents of urban areas are less likely to develop malaria. However, evidence from literature indicates that many urban communities observe poor sanitation practices ${ }^{30}$. Poor sanitation and drainage practices have been identified as risk factors for malaria in urban $\operatorname{areas}^{30}$. The societal hustle and bustle in urban settings and the need to meet financial demands, therefore could dissuade many urban residents from paying visits to healthcare facilities when malaria infection is suspected. To promote healthy societies in urban settings and avoid economic losses associated with severe malaria, the Ministry of Health at national and state levels should liaise with labor organizations to include malaria awareness programs in their schedule at regular intervals.

It is noteworthy that more people enrolled for malaria tests before than during the pandemic, even though it was not statistically significant. Generally, it is uncommon for people in Nigeria to run malaria tests as they will rather treat it with antimalarial medications when they suspect some symptoms than enroll for tests. This finding could be attributed to the fear of exposure to healthcare workers since many healthcare workers were confirmed COVID-19 positive cases. Of the population sampled, there were more positive malaria results before the COVID-19 pandemic than during the COVID-19 pandemic. This could result from the similarities between COVID-19 and malaria symptoms as established from the literature ${ }^{26,27}$. Although malaria is endemic in Nigeria, the close similarities between malaria and COVID-19 symptoms caused confusion among many. Furthermore, the novelty of COVID-19 and lack of sufficient knowledge about it promoted public skepticism regarding its existence. The Federal Ministry of Health and the Nigeria Centre for Disease Control, under the auspices of the Africa Centre for Disease Control, sponsored many health campaigns to debunk fallacies and myths related to COVID-1922,23. Yet, many individuals entertained misconceptions on COVID-19. To this end, many individuals in Nigeria who eventually tested positive for COVID-19 could have initially thought they had malaria. As a result, malarial treatment could have commenced before COVID-19 screening was considered ${ }^{22,23}$. Likewise, they may have used artemisinin-combination therapies (ACTs) over the counter. Irrational use of ACTs could hinder the effectiveness of antimalarial medications and cause antimalarial resistance. For this cause, antimalarial stewardship interventions aimed at promoting rational use of antimalarials only when prescribed by a skilled health professional need to be promoted.

COVID-19 testing is often considered as a last resort for many people following the persistence of symptoms such as anosmia (inability to smell) or the development of complications, such as breathing difficulties. Data from clinical and virological studies have reported that the shedding of SARS-CoV-2, the causative organism for COVID-19, is highest in the first three days of infection. During this period, the viremia level is at its peak. Given the effectiveness of antimalarials in the clinical management of COVID-19 cases, the use of antimalarials could lead to a significant reduction in the virus load before COVID-19 tests are conducted ${ }^{24}$. Thus, many COVID-19 tests may yield negative results since the period of high infectiousness has been bypassed.

\section{Strengths and limitations}

The absence of weights in the calculation of the sample size limits the generalizability of the study. Details such as exact population group, and geographical distribution of respondents were not adequately captured in the original data. Despite these limitations, this study provided knowledge on the differences in the uptake of malarial intervention programs before and during the COVID-19 pandemic. We also reported the factors responsible for the observed results during the COVID-19 pandemic. 


\section{CONCLUSIONS}

The COVID-19 pandemic had a negative impact on some components of malaria intervention coverage in Nigeria, namely malarial testing and visits to health facilities for malarial treatment. To ensure a steady decline in the malaria disease burden, malarial intervention coverage programs, such as antimalarial stewardship should be promoted. This would include the provision of rapid diagnostic kits for community pharmacists. These kits would enable the prompt diagnosis of malarial infection by detecting malaria antigens in the blood. Furthermore, malaria diagnosis should be linked with COVID-19 screening and testing of suspected or confirmed COVID-19 cases to avoid misdiagnosis and enable easy management. Because fever is a common symptom in both diseases, this study emphasizes the need to educate healthcare providers and individuals about the possibility for misdiagnosis of malaria for COVID-19, including the co-existence of the two infections. More and regular ITNs distributions are needed to ensure the prevention of malaria. Improved healthcare leadership and management should be prioritized to reduce health services disruption in Nigeria in a bid to promote population health. These would help to preserve the gains already made from previous malaria programs.

\section{REFERENCES}

1. Lake MA. What we know so far: COVID-19 current clinical knowledge and research. Clin Med (Lond). 2020;20(2):124127. doi:10.7861/clinmed.2019-coron

2. Coronavirus Cases. Worldometer. Updated September 8, 2021. Accessed May 17, 2021. https://www.worldometers. info/coronavirus/coronavirus-cases/

3. Wilder-Smith A, Bar-Yam Y, Fisher D. Lockdown to contain COVID-19 is a window of opportunity to prevent the second wave. J Travel Med. 2020;27(5):taaa091. doi:10.1093/jtm/taaa091

4. Verschuur J, Koks EE, Hall JW. Global economic impacts of COVID-19 lockdown measures stand out in highfrequency shipping data. PLoS One. 2021;16(4):e0248818. doi:10.1371/journal.pone.0248818

5. Nigeria hospital shuts down over COVID-19 fears. Anadolu Agency. April 21, 2021. Accessed May 17, 2021. https:// www.aa.com.tr/en/africa/nigeria-hospital-shuts-downover-covid-19-fears/1813043

6. World Health Organization. World malaria report 2015. 2015. Accessed May 17, 2021. https://apps.who.int/iris/ bitstream/handle/10665/200018/9789241565158_eng. pdf?sequence $=1$ \&isAllowed $=y$

7. World Health Organization. Guidance on temporary malaria control measures in Ebola-affected countries. 2014. Updated November 13, 2014. Accessed May 17, 2021. https://apps. who.int/iris/rest/bitstreams/632221/retrieve

8. World Health Organization. Global technical strategy for malaria 2016-2030. 2015. Accessed May 17, 2021. https:// apps.who.int/iris/rest/bitstreams/795089/retrieve
9. Oyadiran OT, Agaga LA, Adebayo Adebisi Y, LuceroPrisno DE. Nigeria, COVID-19 and the dearth of health workers. J Glob Health. 2020;10(2):020379. doi:10.7189/jogh.10.020379

10. Ezenduka CC, Falleiros DR, Godman BB. Evaluating the Treatment Costs for Uncomplicated Malaria at a Public Healthcare Facility in Nigeria and the Implications. Pharmacoecon Open. 2017;1(3):185-194. doi:10.1007/s41669-017-0021-8

11. Weiss DJ, Bertozzi-Villa A, Rumisha SF, et al. Indirect effects of the COVID-19 pandemic on malaria intervention coverage, morbidity, and mortality in Africa: a geospatial modelling analysis. Lancet Infect Dis. 2021;21(1):59-69. doi:10.1016/S1473-3099(20)30700-3

12. Roser M, Ritchie H. Malaria. Our World In Data. November 2015. Updated October 2019. Accessed August 13, 2021. https://ourworldindata.org/malaria

13. Hogan AB, Jewell BL, Sherrard-Smith E, et al. Potential impact of the COVID-19 pandemic on HIV, tuberculosis, and malaria in low-income and middle-income countries: a modelling study. Lancet Glob Heal. 2020;8(9):e1132-1141. doi:10.1016/S2214-109X(20)30288-6

14. Institute for Health Metrics and Evaluation, Bill and Melinda Gates Foundation, Premise Data Corporation. Premise Malaria COVID-19 Health Services Disruption Survey 2020. Institute for Health Metrics and Evaluation; 2020. doi:10.6069/CZH4-HE51

15. Ade Ajayi JF, Kirk-Greene AHM, Udo RK, Falola TO; The Editors of Encyclopaedia Britannica. Nigeria. Britannica. Accessed May 17, 2021. https://www.britannica.com/place/ Nigeria

16. IBM SPSS Statistics. Version 25.0. IBM Corp; 2017. Updated July 12, 2019. Accessed August 13, 2021. https://www. ibm.com/support/pages/release-notes-ibm\%C2\%AEspss $\%$ C $2 \%$ AE-statistics- 250

17. Centers for Disease Control and Prevention. Confronting Malaria on the Frontline in Nigeria. Updated April 17, 2018. Accessed August 11, 2021. https://www.cdc.gov/ globalhealth/stories/confronting_malaria_on_the_frontline. html

18. Kindzeka ME. COVID-19 Frightens Malaria Patients in Cameroon. Voice of America. April 25, 2020. Accessed May 17, 2021. https://www.voanews.com/science-health/covid19-frightens-malaria-patients-cameroon

19. Recht J, Siqueira AM, Monteiro WM, Herrera SM, Herrera S, Lacerda MVG. Malaria in Brazil, Colombia, Peru and Venezuela: current challenges in malaria control and elimination. Malar J. 2017;16(1):273. doi:10.1186/s12936-017-1925-6

20. Oleribe 00, Ezieme IP, Oladipo O, Akinola EP, Udofia D, Taylor-Robinson SD. Industrial action by healthcare workers in Nigeria in 2013-2015: an inquiry into causes, consequences and control-a cross-sectional descriptive study. Hum Resour Health. 2016;14(1):46. doi:10.1186/s12960-016-0142-7

21. Ilesanmi OS, Afolabi AA. COVID-19 waves in Africa: Effects 
of outbreak response and interventions. Global Biosecurity. 2021;3(1). doi:10.31646/gbio.104

22. Adejoro L. How Lagosians have been mistaking COVID-19 for malaria. PUNCH. August 2, 2020. Accessed August 7, 2021. https://punchng.com/how-lagosians-have-been-mistakingcovid-19-for-malaria-commissioner/

23. Dickson. Don't Mistake COVID-19 For Malaria, FG Warns. Leadership. 2020. Accessed August 7, 2021. https:// leadership.ng/dont-mistake-covid-19-for-malaria-fg-warns/

24. Amimo F, Lambert B, Magit A. What does the COVID-19 pandemic mean for HIV, tuberculosis, and malaria control? Trop Med Health. 2020;48:32. doi:10.1186/s41182-020-00219-6

25. Rogerson SJ, Beeson JG, Laman M, et al. Identifying and combating the impacts of COVID-19 on malaria. BMC Med. 2020;18:239. doi:10.1186/s12916-020-01710-x

26. Black JRM, Bailey C, Przewrocka J, Dijkstra KK, Swanton C. COVID-19: the case for health-care worker screening to prevent hospital transmission. Lancet. 2020;395(10234):1418-1420. doi:10.1016/S0140-6736(20)30917-X

27. Teboh-Ewungkem MI, Ngwa GA. COVID-19 in malariaendemic regions: potential consequences for malaria intervention coverage, morbidity, and mortality. Lancet Infect Dis. 2021;21(1):5-6. doi:10.1016/S1473-3099(20)30763-5

28. Diiro GM, Affognon HD, Muriithi BW, Wanja SK, Mbogo C, Mutero C. The role of gender on malaria preventive behaviour among rural households in Kenya. Malar J. 2016;15:14. doi:10.1186/s12936-015-1039-y

29. National Population Commission, ICF. 2018 Nigeria Demographic and Health Survey Key Findings. National Population Commission, ICF; 2019. Accessed August 13, 2021. https://dhsprogram.com/pubs/pdf/SR264/SR264.pdf

30. Mathanga DP, Tembo AK, Mzilahowa T, et al. Patterns and determinants of malaria risk in urban and periurban areas of Blantyre, Malawi. Malar J. 2016;15:590. doi:10.1186/s12936-016-1623-9

\section{CONFLICTS OF INTEREST}

The authors have completed and submitted the ICMJE Form for Disclosure of Potential Conflicts of Interest and none was reported.

FUNDING

There was no source of funding for this research.

\section{ETHICAL APPROVAL AND INFORMED CONSENT}

This research was conducted in line with the Helsinki declaration. The anonymity of study respondents was ensured by Premise in accordance with the Health Insurance Portability and Accountability Act DeIdentification Standard. Because this research used secondary data, no ethical approval was directly required to conduct this study.

\section{DATA AVAILABILITY}

Data sharing is not applicable to this article as no new data were created.

\section{AUTHORS' CONTRIBUTIONS}

OSI: Conceptualization, data acquisition, methodology, review, and final editing of the manuscript. AAA: Conceptualization, methodology, drafting of the manuscript, review, and final editing of the manuscript. OPI: Drafting of the manuscript, review, and final editing of the manuscript.

PROVENANCE AND PEER REVIEW

Not commissioned; externally peer reviewed. 